\title{
Non-viral iPSCs: a safe way for therapy?
}

\author{
Weiqi Zhang $^{1 *}$, Di Guan ${ }^{1 *}$, Jing Qu ${ }^{1 凶}$, Weizhou Zhang ${ }^{2}$, Guang-Hui Liu ${ }^{1 \bowtie}$ \\ ${ }^{1}$ National Laboratory of Biomacromolecules, Institute of Biophysics, Chinese Academy of Sciences, Beijing 100101, China \\ ${ }^{2}$ Laboratory of Gene Regulation and Signal Transduction, Department of Pharmacology, School of Medicine, University of \\ California, San Diego, La Jolla, CA 92093, USA \\ $\triangle$ Correspondence: ghliu@ibp.ac.cn (G.-H. Liu), w4zhang@ucsd.edu (W. Zhang), or jqu@salk.edu (J. Qu)
}

Patients-derived induced pluripotent stem cells (iPSCs) provide an invaluable tool to study mechanisms of human diseases and also a limitless cellular source for clinical transplantation (Takahashi et al., 2007; Yu et al., 2007; Liu et al., 2011a, 2011b; Zhang et al., 2012). Retrovirus- or lentivirus-based delivery systems have been serving as mainstream methods to generate patients-derived iPSCs. However, genomic integrations of reprogramming factors in virally generated iPSCs not only cause insertional mutagenesis but also lead to residual expression of reprogramming factors in iPSCs and their derivatives. Furthermore, several recent studies demonstrated that relative to embryonic stem cells (ESCs), virally induced iPSCs harbor (epi-)genetic and transcriptional abnormalities, including dysregulation of imprinted genes (such as Dlk1-Dio3), gene copy-number variations (CNVs), accumulation of point mutations and aberrant methylation patterns (Mayshar et al., 2010; Gore et al., 2011; Hussein et al., 2011; Laurent et al., 2011; Martins-Taylor et al., 2011; Taapken et al., 2011; Wu and Hochedlinger, 2011; Zhang et al., 2012). Thus, safety is an important issue when using virally generated human iPSCs or their derivatives in a clinical setting.

Various new approaches have been employed to generate genetically unmodified or non-integrative human iPSCs: (1) non-integrative vectors, including episomal vectors, adenoviral vectors, and sendai viral vectors (Yu et al., 2009; Zhou and Freed, 2009; Jia et al., 2010; Ban et al., 2011; Chou et al., 2011; Hiratsuka et al., 2011; Okita et al., 2011); (2) excisable integrating vectors, such as Cre-recombinase excisable viruses, piggyBac transposon (Kaji et al., 2009; Soldner et al., 2009; Woltjen et al., 2009; Yusa et al., 2009; Sommer et al., 2010); (3) DNA-free materials, such as pluripotency-associated recombinant proteins, RNA, and microRNA (Kim et al., 2009; Warren et al., 2010; Miyoshi et al., 2011); (4) small molecules that can facilitate reprogramming (Feng et al.,
2009; Li and Ding, 2010; Efe and Ding, 2011). Here we will briefly summarize recent literatures on episomal vectors- or small molecules-based technologies for generation of iPSCs (Fig. 1).

As an alternative to viral vectors, genomic integration-free episomal vectors are appealing for easy manipulation and relatively high efficiency compared to other non-integrative methods. The Thomson's group firstly reported the use of oriP/EBNA1-based episomal vectors for reprogramming, although the efficiency is low (Yu et al., 2009). Subsequently, Cheng and colleagues utilized an improved version of episomal vector and successfully generated iPSCs from blood cells (Chou et al., 2011). The Yamanaka's lab further upgraded their episomal vectors that were able to simultaneously encode more than one reprogramming factor and/or cassette (OCT3/4, SOX2, KLF4, L-MYC, LIN28 and p53 shRNA) to generate human iPSCs (Okita et al., 2011). Reprogramming based on improved episomal vectors was believed to be efficient, free of genomic integration of transgenes, and represent a step forward to autologous and allologous stem cell therapy. To examine if genetic abnormalities in episome-based iPSCs are present, Cheng and his coworkers recently performed whole-genome sequencing of three different human iPSCs lines based on an improved episomal vector pEB-C5 (Chou et al., 2011), and claimed that the genome of iPSCs derived by episomal vectors was largely intact (Cheng et al., 2012). There was no detectable vector sequence in all three iPSCs lines. 1058-1808 heterozygous single-nucleotide variants (SNVs) without CNVs were detected in the entire genome of each iPSC line. 6 to 12 of these SNVs were found in exonic regions, but about half of them were synonymous changes and the remaining ones did not cluster in genes associated with cancers (Cheng et al., 2012). In addition, this study demonstrated the high similarity between different iPSC lines derived from different donor cells

\footnotetext{
*These authors contributed equally to the work. 


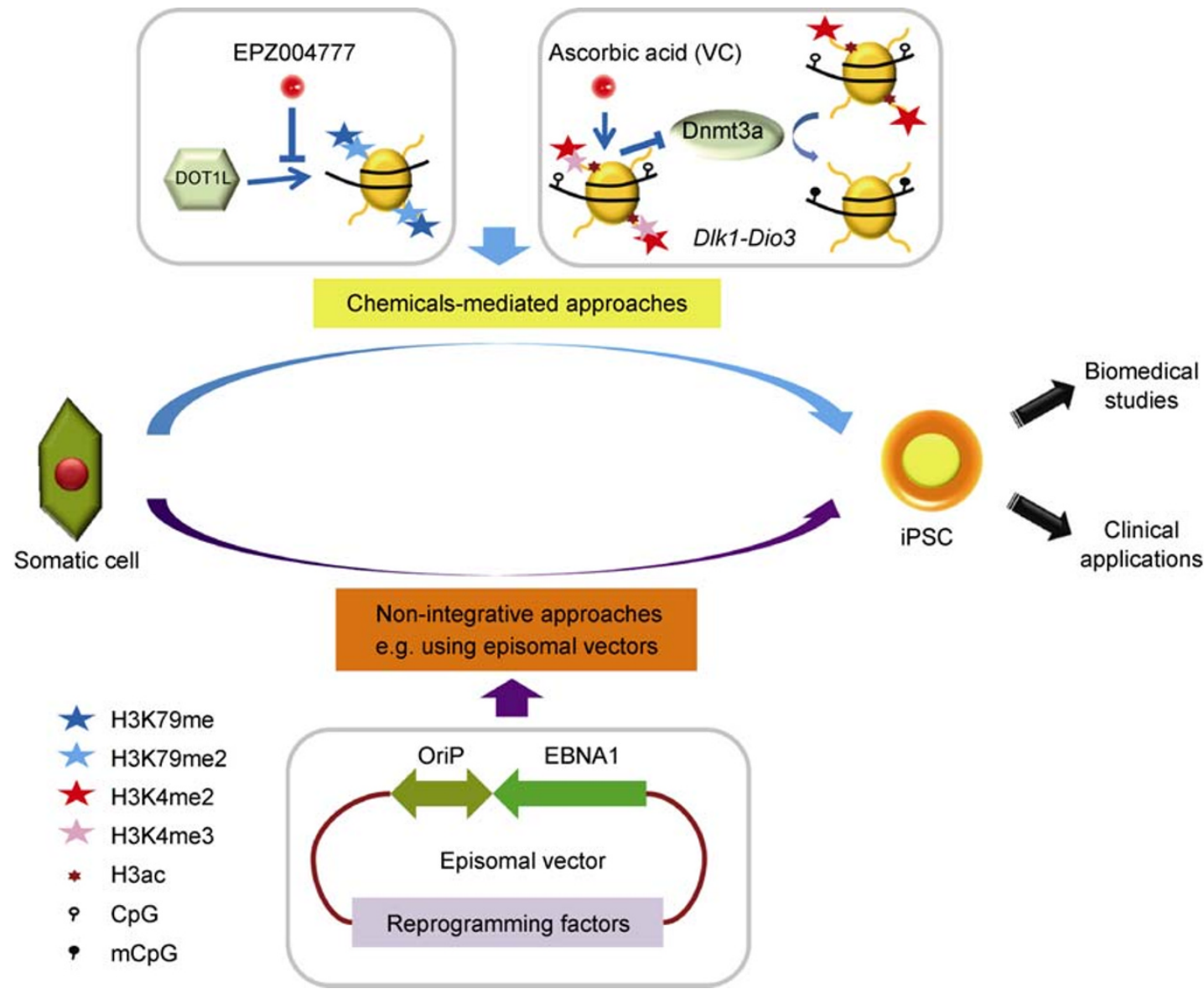

Figure 1. Approaches used to generate "safer" iPSCs.

and with different methods. Another advantage of episomal vector-based iPSCs is their low immunogenic potential compared to virally induced iPSCs (Zhao et al., 2011). Therefore, episomal vector-based reprogramming may hold great potential for stem cell-based therapies, according to their various advantages including high efficiency, genomic integrity, and reduced immunogenicity.

The desire to eventually achieve reprogramming using only chemicals was encouraged by Melton group's work. They demonstrated that chemical compounds such as histone deacetylase (HDAC) and DNA demethylation inhibitors could increase reprogramming efficiency or replace one or more defined reprogramming factors in iPSC system (Huangfu et al., 2008). Later many small-molecule compounds were known to facilitate reprogramming when combined with conventional reprogramming factors ( $\mathrm{Li}$ and Ding, 2010; Efe and Ding, 2011). Of note, the Ding's team reported a chemical cocktail, including Butyrate (an HDAC inhibitor), CHIR99021 (a GSK-3 $\beta$ inhibitor), Parnate (a histone lysine demethylase inhibitor), PD0325901 (a MEK inhibitor), A8301 (a TGF $\beta$ inhibitor) and PS48 (a phosphoinositide-dependent protein kinase-1 activator), reprogrammed human somatic cells into iPSCs with a single factor OCT4 (Zhu et al., 2010), raising the possibility to completely remove protein factors during reprogramming. Among the molecules modulating specific signaling pathway or epigenetic state, ascorbic acid (Vitamin C, VC) is a star chemical, which enhanced reprogramming of mouse somatic cells (the human iPSCs culture medium contains VC) (Esteban et al., 2010). The mechanism of VC's function may link to its downstream factor Jhdm 1a/1b, a histone demethylase responsible for H3K36me2 or H3K36me3 demethylation which in turn accelerates cell proliferation by repressing the Ink4/Arf locus (Wang et al., 2011). New mouse study from the Hochedlinger group showed that VC attenuated hypermethylation of DIk1-Dio3 by disenabling intergenic differentially methylated region (IG-DMR) to recruit Dnmt3a (a DNA methyltransferase) in the progress of reprogramming. Interestingly, mature B cell-derived iPSCs were enabled to generate entire adult mice (all-iPSCs mice) when VC was added to the culture medium (Stadtfeld et al., 2012). The results are in agreement with a previous report that iPSCs with aberrant silenced Dlk1-Dio3 cluster failed to yield viable all-iPSCs mice (Stadtfeld et al., 2010). These findings strongly indicate that compounds added in reprogramming and/or culture media have profound effects on the epigenetic and biological properties of the derived iPSCs. Another ex- 
ample to prove epigenetic modulators could regulate reprogramming was presented by Onder and his colleagues. They demonstrated that inactivation of DOT1L (an H3K79 methyltransferase) by shRNA or small molecule (EPZ004777) enhanced reprogramming efficiency and led to the removal of KLF4 and C-MYC in reprogramming cocktail, which was accompanied with an upregulation of NANOG and LIN28 expression during reprogramming (Onder et al., 2012). The same group also showed that inhibition of PRC1 (polycomb repressive complex1, including BMI1 and RING1) and PRC2 (polycomb repressive complex 2, including EZH2, EED and SUZ12) reduced reprogramming efficiency, while suppression of SUV39H1 and YY1 enhanced reprogramming (Onder et al., 2012). Among them, PRC2 facilitated the generation of H3K27me3, a modification associated with stable epigenetic silencing (Swigut and Wysocka, 2007). A previous report has revealed that expression of PRC2 could enhance reprogramming of mouse embryonic fibroblast (MEF) into iPSCs (Zhang et al., 2011). It is noteworthy that either loss of H3K79me2 or gain of H3K27me3 could down-regulate the expression of lineage-associated genes and promote erasure of fibroblast "memories," which is the initiative step of reprogramming process (Zhang et al., 2011; Onder et al., 2012). Additionally, other chromatin-remodeling components like BAF and WDR5 were also shown to facilitate reprogramming (Singhal et al., 2010; Ang et al., 2011). Altogether, these findings provide strong evidence on how specific chemicals can be exploited to facilitate iPSCs generation with fewer exogenous transcription factors by regulating chromatin-modifying enzymes..

Significant progress has been made towards "safe" iPSCs with non-integrative vector or based on small molecules. Episomal vector-based technology is still based on protein factors to induce pluripotent state from somatic cells, but has clear advantages over viral delivering system. Whole genomic deep sequencing of established iPSC lines from different patients reveals a negligible effect of episomal delivering system in random genomic modifications (Cheng et al., 2012). Although episomal vector-based delivery is not as efficient as viral vectors, it is a relative safe method to generate patient-specific iPSCs for potential autologous cell replacement therapy. Unexpectedly, episomal delivering method generates SNVs containing sense mutations in genomes and leaves an important safety concern. An alternative and relatively safe method to generate iPSCs is based on using small-molecule compounds. Various chemicals, including those involved in epigenetic modification, mesenchymal-to-epithelial transition (MET), cell senescence, and metabolism, have been known as critical regulators of somatic reprogramming. Recent advance in the Ding laboratory paves the way to induce pluripotency in a protein-free system (Li and Ding, 2010; Efe and Ding, 2011). Using a chemically defined system makes it possible to avoid any unexpected modification on the genome of iPSCs or their derivatives and represents a promising strategy for safe and controlled iPSCs generation. Another advantage to use small molecules with defined activities to cellular signaling pathways or proteins is to dissect the extremely complicated process associated with reprogramming. It is very important to study the molecular mechanisms involved in induced pluripotency from somatic cells, as well as the pathogenic mechanisms of certain inheritable diseases (e.g. Parkinson's disease). Thus chemicals-based iPSCs hold great importance of both scientific research and clinical applications. Similar approaches mentioned above could be also applicable to other important areas including direct conversion of somatic cells into lineage-committed cells to evade pluripotent state.

\section{ACKNOWLEDGEMENTS}

G.H.L. is supported by 100 Talents Program of Chinese Academy of Sciences and a CIRM grant. J.Q. is supported by an AFAR/Ellison Medical Foundation postdoctoral fellowship. W.Z. is supported by NIH Pathway to Independence award (K99/R00 CA158055-01).

\section{REFERENCES}

Ang, Y.S., Tsai, S.Y., Lee, D.F., Monk, J., Su, J., Ratnakumar, K., Ding, J., Ge, Y., Darr, H., Chang, B., et al. (2011). Wdr5 mediates self-renewal and reprogramming via the embryonic stem cell core transcriptional network. Cell 145, 183-197.

Ban, H., Nishishita, N., Fusaki, N., Tabata, T., Saeki, K., Shikamura, M., Takada, N., Inoue, M., Hasegawa, M., Kawamata, S., et al. (2011). Efficient generation of transgene-free human induced pluripotent stem cells (iPSCs) by temperature-sensitive Sendai virus vectors. Proc Natl Acad Sci U S A 108, 14234-14239.

Cheng, L., Hansen, N.F., Zhao, L., Du, Y., Zou, C., Donovan, F.X., Chou, B.K., Zhou, G., Li, S., Dowey, S.N., et al., and the NISC Comparative Sequencing Program. (2012). Low incidence of DNA sequence variation in human induced pluripotent stem cells generated by nonintegrating plasmid expression. Cell Stem Cell 10, 337-344.

Chou, B.-K., Mali, P., Huang, X., Ye, Z., Dowey, S.N., Resar, L.M.S., Zou, C., Zhang, Y.A., Tong, J., and Cheng, L. (2011). Efficient human iPS cell derivation by a non-integrating plasmid from blood cells with unique epigenetic and gene expression signatures. Cell Res 21, 518-529.

Efe, J.A., and Ding, S. (2011). The evolving biology of small molecules: controlling cell fate and identity. Philos Trans R Soc Lond B Biol Sci 366, 2208-2221.

Esteban, M.A., Wang, T., Qin, B., Yang, J., Qin, D., Cai, J., Li, W., Weng, Z., Chen, J., Ni, S., et al. (2010). Vitamin C enhances the generation of mouse and human induced pluripotent stem cells. Cell Stem Cell 6, 71-79.

Feng, B., Ng, J.H., Heng, J.C., and Ng, H.H. (2009). Molecules that promote or enhance reprogramming of somatic cells to induced pluripotent stem cells. Cell Stem Cell 4, 301-312. 
Gore, A., Li, Z., Fung, H.-L., Young, J.E., Agarwal, S., Antosiewicz-Bourget, J., Canto, I., Giorgetti, A., Israel, M.A., Kiskinis, E., et al. (2011). Somatic coding mutations in human induced pluripotent stem cells. Nature 471, 63-67.

Hiratsuka, M., Uno, N., Ueda, K., Kurosaki, H., Imaoka, N., Kazuki, K., Ueno, E., Akakura, Y., Katoh, M., Osaki, M., et al. (2011). Integration-free iPS cells engineered using human artificial chromosome vectors. PLoS One 6, e25961.

Huangfu, D., Maehr, R., Guo, W., Eijkelenboom, A., Snitow, M., Chen, A.E., and Melton, D.A. (2008). Induction of pluripotent stem cells by defined factors is greatly improved by small-molecule compounds. Nat Biotechnol 26, 795-797.

Hussein, S.M., Batada, N.N., Vuoristo, S., Ching, R.W., Autio, R., Närvä, E., Ng, S., Sourour, M., Hämäläinen, R., Olsson, C., et al. (2011). Copy number variation and selection during reprogramming to pluripotency. Nature 471, 58-62.

Jia, F., Wilson, K.D., Sun, N., Gupta, D.M., Huang, M., Li, Z., Panetta, N.J., Chen, Z.Y., Robbins, R.C., Kay, M.A., et al. (2010). A nonviral minicircle vector for deriving human iPS cells. Nat Methods 7 , 197-199.

Kaji, K., Norrby, K., Paca, A., Mileikovsky, M., Mohseni, P., and Woltjen, K. (2009). Virus-free induction of pluripotency and subsequent excision of reprogramming factors. Nature 458, 771-775.

Kim, D., Kim, C.-H., Moon, J.-I., Chung, Y.-G., Chang, M.-Y., Han, B.-S., Ko, S., Yang, E., Cha, K.Y., Lanza, R., et al. (2009). Generation of human induced pluripotent stem cells by direct delivery of reprogramming proteins. Cell Stem Cell 4, 472-476.

Laurent, L.C., Ulitsky, I., Slavin, I., Tran, H., Schork, A., Morey, R., Lynch, C., Harness, J.V., Lee, S., Barrero, M.J., et al. (2011). Dynamic changes in the copy number of pluripotency and cell proliferation genes in human ESCs and iPSCs during reprogramming and time in culture. Cell Stem Cell 8, 106-118.

Li, W., and Ding, S. (2010). Small molecules that modulate embryonic stem cell fate and somatic cell reprogramming. Trends Pharmacol Sci 31, 36-45.

Liu, G.H., Barkho, B.Z., Ruiz, S., Diep, D., Qu, J., Yang, S.L., Panopoulos, A.D., Suzuki, K., Kurian, L., Walsh, C., et al. (2011a). Recapitulation of premature ageing with iPSCs from Hutchinson-Gilford progeria syndrome. Nature 472, 221-225.

Liu, G.H., Suzuki, K., Qu, J., Sancho-Martinez, I., Yi, F., Li, M., Kumar, S., Nivet, E., Kim, J., Soligalla, R.D., et al. (2011b). Targeted gene correction of laminopathy-associated LMNA mutations in patient-specific iPSCs. Cell Stem Cell 8, 688-694.

Martins-Taylor, K., Nisler, B.S., Taapken, S.M., Compton, T., Crandall, L., Montgomery, K.D., Lalande, M., and Xu, R.-H. (2011). Recurrent copy number variations in human induced pluripotent stem cells. Nat Biotechnol 29, 488-491.

Mayshar, Y., Ben-David, U., Lavon, N., Biancotti, J.-C., Yakir, B., Clark, A.T., Plath, K., Lowry, W.E., and Benvenisty, N. (2010). Identification and classification of chromosomal aberrations in human induced pluripotent stem cells. Cell Stem Cell 7, 521-531.

Miyoshi, N., Ishii, H., Nagano, H., Haraguchi, N., Dewi, D.L., Kano, Y., Nishikawa, S., Tanemura, M., Mimori, K., Tanaka, F., et al. (2011). Reprogramming of mouse and human cells to pluripotency using mature microRNAs. Cell Stem Cell 8, 633-638.

Nguyen, A.T., and Zhang, Y. (2011). The diverse functions of Dot1 and H3K79 methylation. Genes Dev 25, 1345-1358.

Okita, K., Matsumura, Y., Sato, Y., Okada, A., Morizane, A., Okamoto, S., Hong, H., Nakagawa, M., Tanabe, K., Tezuka, K., et al. (2011). A more efficient method to generate integration-free human iPS cells. Nat Methods 8, 409-412.

Onder, T.T., Kara, N., Cherry, A., Sinha, A.U., Zhu, N., Bernt, K.M., Cahan, P., Mancarci, O.B., Unternaehrer, J., Gupta, P.B., et al. (2012). Chromatin-modifying enzymes as modulators of reprogramming. Nature 483, 598-602.

Singhal, N., Graumann, J., Wu, G., Araúzo-Bravo, M.J., Han, D.W., Greber, B., Gentile, L., Mann, M., and Schöler, H.R. (2010). Chromatin-Remodeling Components of the BAF Complex Facilitate Reprogramming. Cell 141, 943-955.

Soldner, F., Hockemeyer, D., Beard, C., Gao, Q., Bell, G.W., Cook, E.G., Hargus, G., Blak, A., Cooper, O., Mitalipova, M., et al. (2009). Parkinson's disease patient-derived induced pluripotent stem cells free of viral reprogramming factors. Cell 136, 964-977.

Sommer, C.A., Sommer, A.G., Longmire, T.A., Christodoulou, C., Thomas, D.D., Gostissa, M., Alt, F.W., Murphy, G.J., Kotton, D.N., and Mostoslavsky, G. (2010). Excision of reprogramming transgenes improves the differentiation potential of iPS cells generated with a single excisable vector. Stem Cells 28, 64-74.

Stadtfeld, M., Apostolou, E., Akutsu, H., Fukuda, A., Follett, P., Natesan, S., Kono, T., Shioda, T., and Hochedlinger, K. (2010). Aberrant silencing of imprinted genes on chromosome 12qF1 in mouse induced pluripotent stem cells. Nature 465, 175-181.

Stadtfeld, M., Apostolou, E., Ferrari, F., Choi, J., Walsh, R.M., Chen, T., Ooi, S.S.K., Kim, S.Y., Bestor, T.H., Shioda, T., et al. (2012). Ascorbic acid prevents loss of Dlk1-Dio3 imprinting and facilitates generation of all-iPS cell mice from terminally differentiated B cells. Nat Genet 44, 398-405.

Swigut, T., and Wysocka, J. (2007). H3K27 demethylases, at long last. Cell 131, 29-32.

Taapken, S.M., Nisler, B.S., Newton, M.A., Sampsell-Barron, T.L., Leonhard, K.A., McIntire, E.M., and Montgomery, K.D. (2011). Karotypic abnormalities in human induced pluripotent stem cells and embryonic stem cells. Nat Biotechnol 29, 313-314.

Takahashi, K., Tanabe, K., Ohnuki, M., Narita, M., Ichisaka, T., Tomoda, K., and Yamanaka, S. (2007). Induction of pluripotent stem cells from adult human fibroblasts by defined factors. Cell 131, 861-872.

Wang, T., Chen, K., Zeng, X., Yang, J., Wu, Y., Shi, X., Qin, B., Zeng, L., Esteban, M.A., Pan, G., et al. (2011). The histone demethylases $\mathrm{Jhdm} 1 \mathrm{a} / 1 \mathrm{~b}$ enhance somatic cell reprogramming in a vitamin-C-dependent manner. Cell Stem Cell 9, 575-587.

Warren, L., Manos, P.D., Ahfeldt, T., Loh, Y.-H., Li, H., Lau, F., Ebina, W., Mandal, P.K., Smith, Z.D., Meissner, A., et al. (2010). Highly efficient reprogramming to pluripotency and directed differentiation of human cells with synthetic modified mRNA. Cell Stem Cell 7, 618-630.

Woltjen, K., Michael, I.P., Mohseni, P., Desai, R., Mileikovsky, M., 
Hämäläinen, R., Cowling, R., Wang, W., Liu, P., Gertsenstein, M., et al. (2009). piggyBac transposition reprograms fibroblasts to induced pluripotent stem cells. Nature 458, 766-770.

Wu, S.M., and Hochedlinger, K. (2011). Harnessing the potential of induced pluripotent stem cells for regenerative medicine. Nat Cell Biol 13, 497-505.

Yu, J., Hu, K., Smuga-Otto, K., Tian, S., Stewart, R., Slukvin, I.I., and Thomson, J.A. (2009). Human induced pluripotent stem cells free of vector and transgene sequences. Science 324, 797-801.

Yu, J., Vodyanik, M.A., Smuga-Otto, K., Antosiewicz-Bourget, J., Frane, J.L., Tian, S., Nie, J., Jonsdottir, G.A., Ruotti, V., Stewart, $\mathrm{R}$., et al. (2007). Induced pluripotent stem cell lines derived from human somatic cells. Science 318, 1917-1920.

Yusa, K., Rad, R., Takeda, J., and Bradley, A. (2009). Generation of transgene-free induced pluripotent mouse stem cells by the piggyBac transposon. Nat Methods 6, 363-369.
Zhang, W., Ding, Z., and Liu, G.H. (2012). Evolution of iPSC disease models. Protein Cell 3, 1-4.

Zhang, Z., Jones, A., Sun, C.W., Li, C., Chang, C.W., Joo, H.Y., Dai, Q., Mysliwiec, M.R., Wu, L.C., Guo, Y., et al. (2011). PRC2 complexes with JARID2, MTF2, and esPRC2p48 in ES cells to modulate ES cell pluripotency and somatic cell reprogramming. Stem Cells 29, 229-240.

Zhao, T., Zhang, Z.-N., Rong, Z., and Xu, Y. (2011). Immunogenicity of induced pluripotent stem cells. Nature 474, 212-215.

Zhou, W., and Freed, C.R. (2009). Adenoviral gene delivery can reprogram human fibroblasts to induced pluripotent stem cells. Stem Cells 27, 2667-2674.

Zhu, S., Li, W., Zhou, H., Wei, W., Ambasudhan, R., Lin, T., Kim, J., Zhang, K., and Ding, S. (2010). Reprogramming of human primary somatic cells by OCT4 and chemical compounds. Cell Stem Cell 7, 651-655. 